\title{
DAMAGE LOCALIZATION AND MONITORING OF LOAD CHANGES IN TRUSS STRUCTURES
}

\begin{abstract}
In recent years one can observe an increasing interest of the researchers, both from academia and industry, in the development of systems for the monitoring of health structures.. The main fields of application for these systems are rotating machinery, aircrafts and other means of group transport and civil engineering structures. Many of the latter, contain truss elements in its structure. That is why detection and possible localization of the fault in such a structures is crucial for the safety of its operation. In this paper the application of modal filtration to damage detection and localization in the truss structures is presented. The results of numerical simulation an laboratory experiment are shown.
\end{abstract}

Keywords: damage detection, damage localization, truss structures, modal filter

\section{LOKALIZACJA USZKODZEŃ I MONITOROWANIE ZMIAN OBCIAZŻENIA W STRUKTURACH KRATOWNICOWYCH}

Ostatnio można zaobserwować wzrastajace zainteresowanie badaczy zarówno ze środowisk akademickich, jak $i$ z przemystu, rozwojem układów monitorowania stanu obiektów. Główne pola zastosowania tych układów to maszyny wirnikowe, lotnictwo i inne środki transportu zbiorowego oraz konstrukcje inżynierii lqdowej. W artykule pokazano zastosowanie filtracji modalnej do wykrywania i lokalizowania uszkodzeń w konstrukcjach kratownicowych. Przedstawiono wyniki badań symulacyjnych oraz pomiarów laboratoryjnych.

Stowa kluczowe: wykrywanie uszkodzen, lokalizacja uszkodzeń, konstrukcje kratownicowe, filtr modalny

\section{INTRODUCTION}

Nowadays, there are still many civil engineering objects of road and rail infrastructure which were developed 30 or more years ago. The author has mostly in mind bridges and viaducts. These structures are subjected to the destructive effect such as increasing traffic volume and traffic speed, overloading, pollutants, etc. These factors can be a reason of construction defects and damages, which can cause the loss of load-carrying capacity. A result of destructive phenomena mentioned earlier is decreasing the life span of bridges.

Many of operating bridges require immediate repair or rehabilitation. Bridge management companies need to have data to support official to decide upon the necessary activity for uninterrupted and safe service life. The data include information about remaining strength, serviceability and durability. These data can be evaluated based on structural testing of the structure, against data which is collected by visual inspection of bridge structures (commonly used methods for bridge condition assessment). The structural testing procedure to evaluate bridge conditions requires a diagnostic approach based on testing and monitoring. New nondestructive experimental testing methods have become available for bridge condition assessment, now. The selection of appropriate methods should emphasize that results are intended to get practical structural data for future use in designing of maintenance or rehabilitation. Permanent monitoring or periodic testing methods are available in the field. If the structure is critical from a safety point of view the permanent monitoring of structural integrity is preferred. It helps to identify the integrity of bridges every hour, but the cost of instrumentation is relatively high. For economical reasons permanent monitoring is only applied in special cases but the periodic monitoring technique is preferred commonly. The period of structure examination depends on several conditions like; traffic density, bridge design, climate type, severity in road network, etc. In many practical cases the evaluation of bridges conditions are performed only before and after maintenance and rehabilitation. The interpretation of the results of such a test is very difficult if prediction of rest life period is required. There is no possibility to apply simple diagnostic tool such as trend analysis to support the condition prediction process in a case of incidental measurements. But such a diagnostic test can be applied for the condition assessment of particular elements of bridges and support decision about maintenance or rehabilitation depth which have an influence on repair costs.

The structure of these objects is very diverse. There are still many bridges with truss like supporting structures. For these types of structures there is a crucial thing to be able to detect damage in the truss joint, which is a little bit different situation than crack detection in the beam or plate. Another issue that is important in the monitoring of bridges is the detection of overloading. So the ideal algorithm for monitoring of this type of objects should have the following features: ability to detect and localize structural changes also in joint points, detect the changes in loading of the structure and be robust for temperature changes.

One of the groups of damage detection algorithms used in nondestructive testing and structural health monitoring is the group of the so-called vibration methods, i.e. methods that

* AGH University of Science and Technology, Department of Robotics and Mechatronics, Krakow, Poland, e-mail: mendrok@agh.edu.pl 
use data in the form of accelerations of vibrations in time or frequency do-mains. They are based on the observation of changes in the system's vibration responses, which result from damage occurrence. The methods' main idea is model-based diagnostics defined in the following way: the model of a particular system in an undamaged state is given, and this model is compared to the model identified from the data measured on the object in the current state. Differences between these two models indicate the object modification (e.g. stiffness or mass decrease), which may be caused by damage. A detailed description of some of the methods mentioned above, together with its verification can be found in (Mendrok and Uhl 2004, Doebling et al. 1998) and (Carden and Fanning 2004). The most convenient model, which can be applied in the described approach, is a modal model. It is relatively easy to identify and, by means of operational modal analysis, may be identified only from response data; it is, therefore, very useful in diagnostics. Apart from its advantages, the application of modal model-based diagnostics within damage detection has several limitations and faults. First of all, there is a serious problem distinguishing between the changes in parameters resulting from damage and those caused by environmental changes e.g. temperature or humidity. That is especially visible in civil engineering structure monitoring. A further limitation of modal model-based diagnostics involves difficulties with the automation of procedures. Despite the current development of autonomous modal analysis procedures in many scientific centers, the total independence of an engineer's interference is still problematic in practice. Additionally, diagnostic symptoms in the form of natural frequencies, modal damping coefficients and modal vectors are estimated periodically, and depend on the subjective assessment of a testing team. Also, the computational cost required by the modal parameters estimation algorithms is rather high, and makes problematic its implementation on the embedded diagnostic systems.

There is however a method which uses vibration data as well as a modal model of the object and, in addition, overcomes all mentioned above limitations. This is the advantage of modal filtering applied to the data recorded on the object. The goal of this paper is to check if the method is also capable to localize damage of the truss joint and detect changes in loading of the truss structure to indicate the overloading state. The author will show the numerical simulation of fault in the truss joint and will use the modal filtration to detect and localize it Also the laboratory experiment will indicate if the method can detect loading changes. The novelty proposed in the paper is the application of the modal filtration method to localization of joint fault and detection of changes in loading.

\section{DAMAGE DETECTION AND LOCALIZATION WITH THE USE OF MODAL FILTRATION}

The method was originally developed for damage detection (Mendrok and Uhl 2010a). But to present it properly it is first necessary to mention a few words about modal filtration.

The modal filter is a tool to extract the modal coordinates of each individual mode from the system outputs by mapping the response vector from the physical space to the modal space (Zhang et al. 1990). It was first introduced by Baruh and Meirovitch (1982) to overcome the spill-over problem within the control of the distributed parameter systems. Spill-over is a phenomenon in which the energy addressed to the controlled mode is pumped into the uncontrolled modes. To construct the modal filter a new modal parameter was introduced: reciprocal modal vectors $\psi$. They should be orthogonal with respect to all the modal vectors except the one to which the filter is tuned, and, thanks to that, are applied to the decomposition of the system responses to the modal coordinates $\eta_{r}$.

$$
\begin{aligned}
\eta_{r}(\omega) & =\psi_{r}^{T} \cdot\{x(\omega)\}= \\
& =\left(\frac{\left\{\phi_{r}\right\}^{T}}{j \omega-\lambda_{r}}+\left\{\psi_{r}\right\}^{T}\left\{\phi_{r}^{*}\right\} \frac{\left\{\phi_{r}^{*}\right\}^{T}}{j \omega-\lambda_{r}^{*}}\right) \cdot\{f(\omega)\}
\end{aligned}
$$

where:

$$
\begin{gathered}
x(\omega)-\text { vector of system responses, } \\
f(\omega)-\text { vector of inputs, } \\
\phi_{r}-r \text {-th modal vector. }
\end{gathered}
$$

Now, scaling the modal coordinates $\eta_{r}$ by the known input, it is possible to determine the frequency response function (FRF) with all peaks, except $r$-th, filtered out. The way of using modal filtering for structural health monitoring is presented in figure 1.

The FRF of an object filtered with a modal filter has only one peak corresponding to the natural frequency to which the filter is tuned. When a local change occurs in the object - in stiffness or in mass (this mainly happens when damage in the object arises), the filter stops working and, on the output characteristic, other peaks start to appear, corresponding to other imperfectly filtered natural frequencies. On the other hand, a global change in entire stiffness or mass matrix (due to changes in ambient temperature or humidity) does not corrupt the filter and the filtered characteristic still has one peak, although it is slightly moved in the frequency domain.

The method can be further extended to the damage localization. The idea (Mendrok and Uhl 2008, 2011) is based on the fact that damage, in most cases, only disturbs the mode shapes locally. It is then possible to divide an object into areas measured with the use of several sensors and build separate local modal filters for data coming only from these sensors. In areas without damage, the shape of modes does not change and the modal filter keeps working - there are no additional peaks on the filter output. When a group of sensors placed near the damage is considered, mode shape is disturbed locally due to damage and the modal filter does not perfectly filter the characteristics measured by these sensors.

It has been said (Zhang et al. 1990) that the minimum number of sensors required to build an effective modal filter is equal to or greater than the number of modes in the frequency range of interest. Thus, by limiting the frequency range of the analysis to the first two modes, it would be theoretically possible to construct modal filters for object areas measured with only 2 sensors. This would significantly increase the damage location accuracy. 


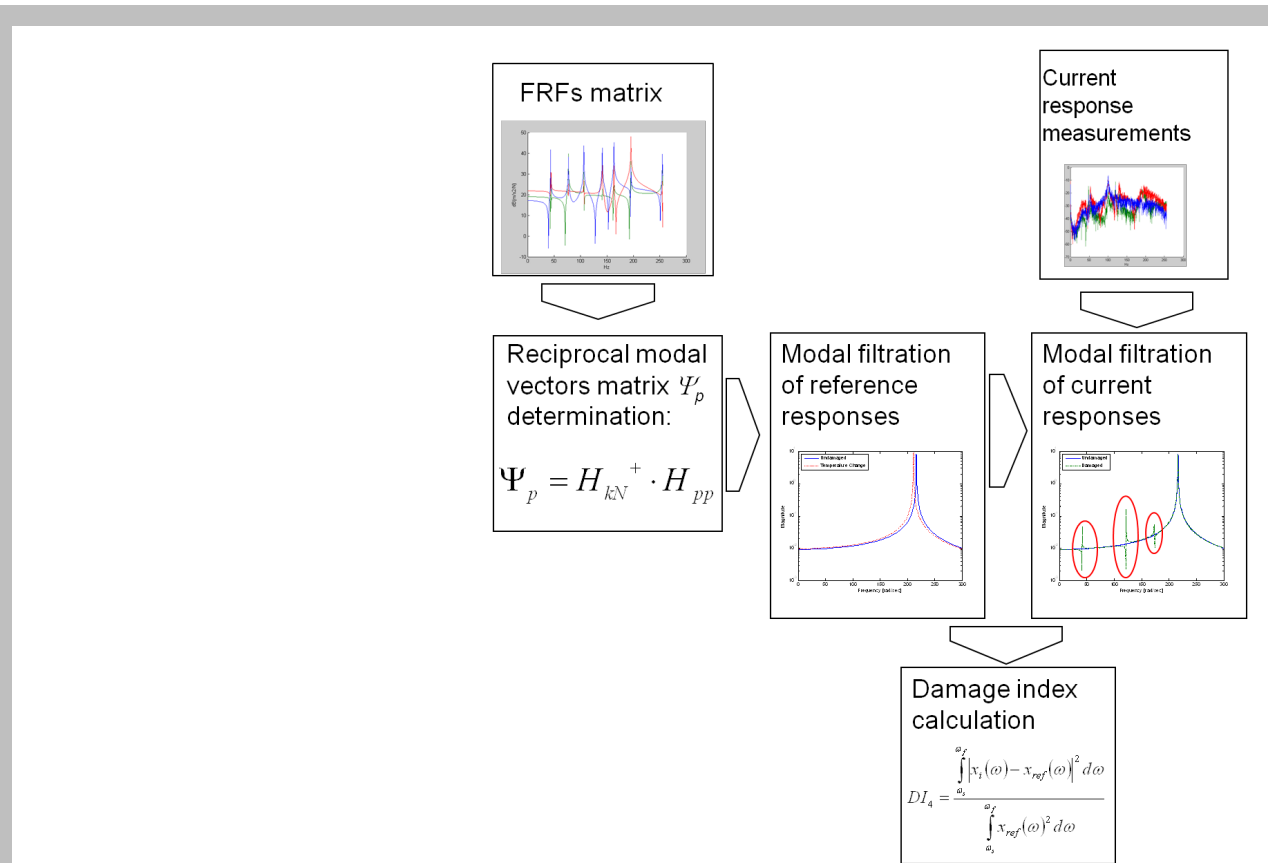

Fig. 1. Procedure for damage detection with the use of modal filtration

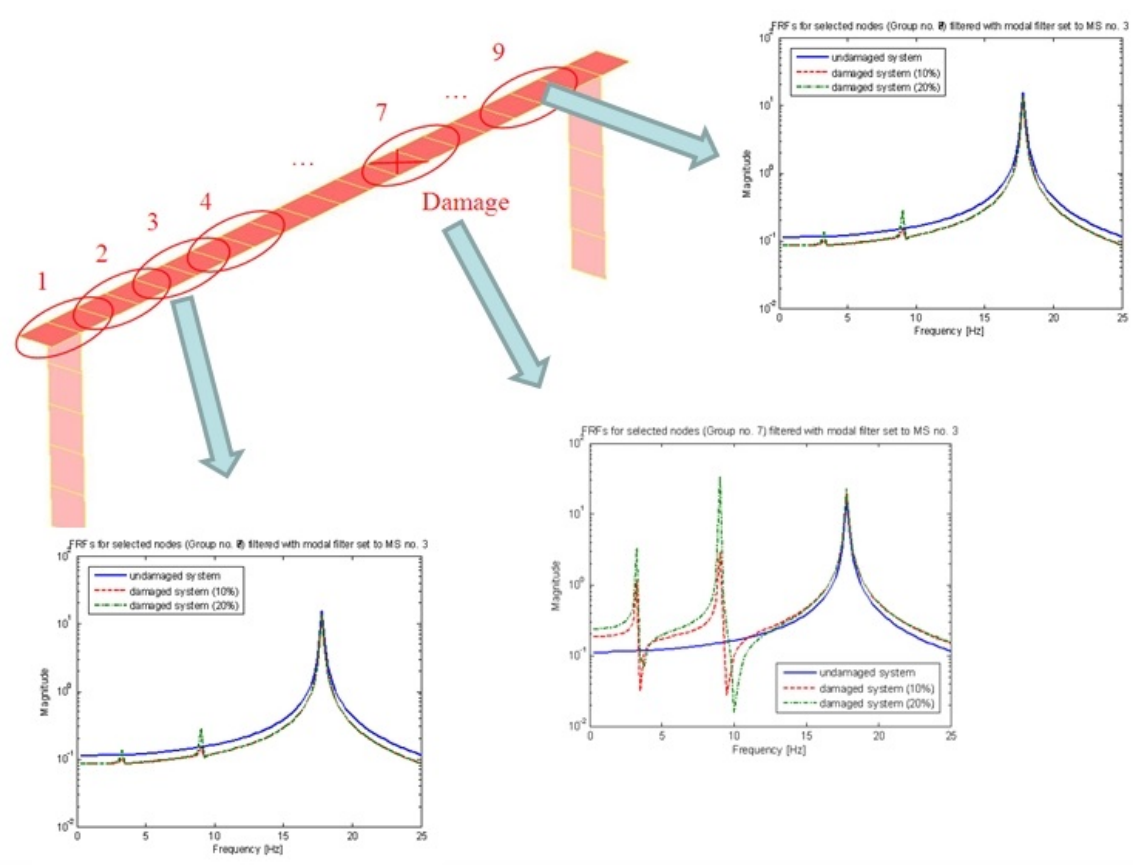

Fig. 2. Scheme of the proposed method of damage localization

In practice, however, to construct the modal filter for two modes, data from at least 4 sensors has to be used. The accuracy of damage localization depends on measuring net density. The graphical presentation of this idea is presented in figure 2 .

To make localization easier, it was decided to use the damage index DI provided by equation (2):

$$
\mathrm{DI}=\frac{\int_{\omega_{s}}^{\omega_{f}}\left|x_{i}(\omega)-x_{r e f}(\omega)\right|^{2} d \omega}{\int_{\omega_{s}}^{\omega_{f}} x_{r e f}(\omega)^{2} d \omega}
$$

\section{where:}

$\omega_{s}$ - starting frequency of the analyzed band,

$\omega_{f}$ - closing frequency of the analyzed band,

$x_{i}$ - characteristic in the current state,

$x_{r e f}-$ characteristic in the reference state.

The DI is calculated only for the frequency regions which directly surround the Natural frequencies of the object, except the one to which the modal filter is tuned. The width of the consecutive frequency intervals was assumed to amount to $20 \%$ of the corresponding natural frequency. For practical applications it would be useful to set the threshold for the difference 


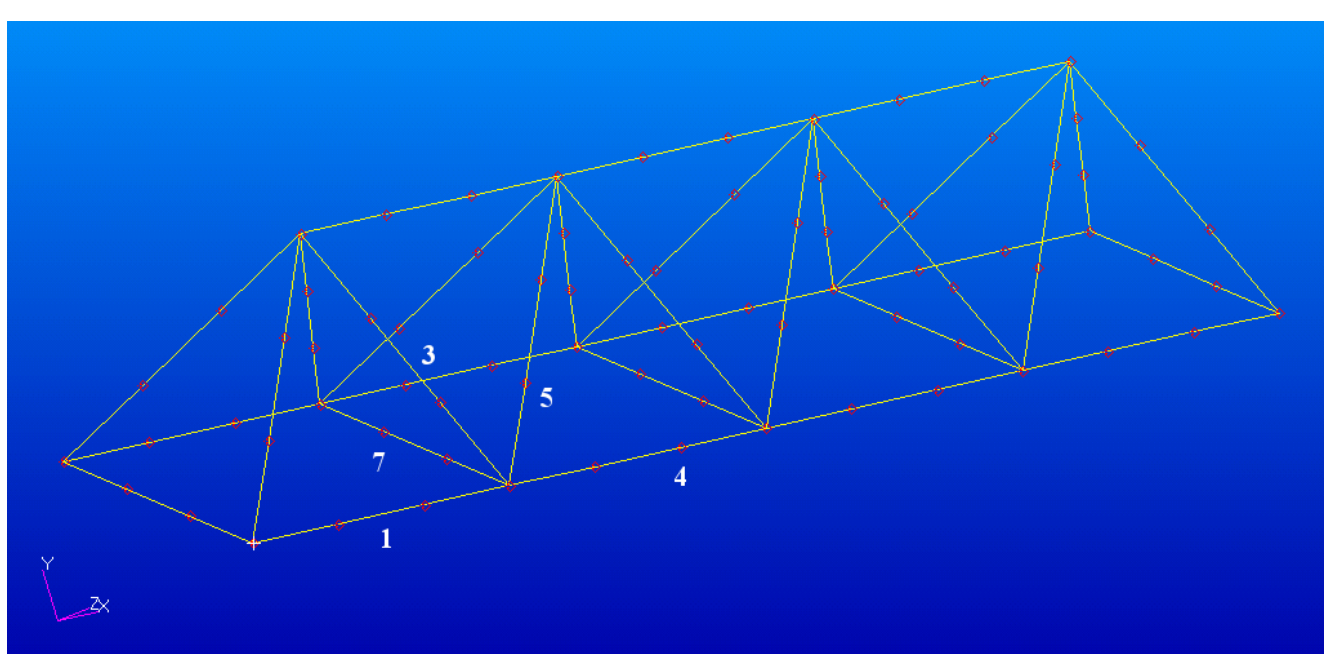

Fig. 3. FE model of analyzed truss

between the damage index value for the regions (groups of sensors) with and without damage. Such a threshold would make it possible to detect the damaged region more easily and even introduce some automation of diagnostic procedure. However, the threshold needs to be assessed individually depending on the object type and minimum damage size to be detected. In the next sections the method will be verified if it is able to localize damage in the truss joint and track the loading change.

\section{DAMAGE LOCALIZATION IN THE JOINT OF THE TRUSS STRUCTURE}

At first the author will try to find out if it is possible to properly localize failure in the joint of the truss structure, This research was carried out on the numerical data. The model with the use of the finite element method was developed and its picture is presented in figure 3 . The model consisted of 96 beam elements and 78 nodes. The cross-section of the elements was defined as a square with length of the side $20 \mathrm{~mm}$. Length of each beam in the truss amounted $3 \mathrm{~m}$. The material properties for all the elements were assumed as steel. The truss was analyzed in free-free conditions. Firstly, the eigenvalue problem was solved for the structure without damage, and from the results the reciprocal modal vectors (modal filter coefficients) and FRF were calculated. The model was then divided into areas containing 4 nodes (virtual sensors) each. Every beam was a separate area and for every area the local modal filter coefficients were calculated as well. The most important areas are numbered in figure 3 .

Next, the damage was introduced. Failure consisted in a total lack of connection (dual-node) of the rod marked number 3 in the damaged joint. According to the definition of the areas described above, the damage was in area 3 neighboring with the areas 1, 4, 5 and 7. Again the eigenvalue problem was solved and FRFs of the damaged system were calculated. The FRFs from the undamaged and damaged structure were filtered with a local modal filter and DI was calculated according to Formula (2). The results are presented in figure 4.

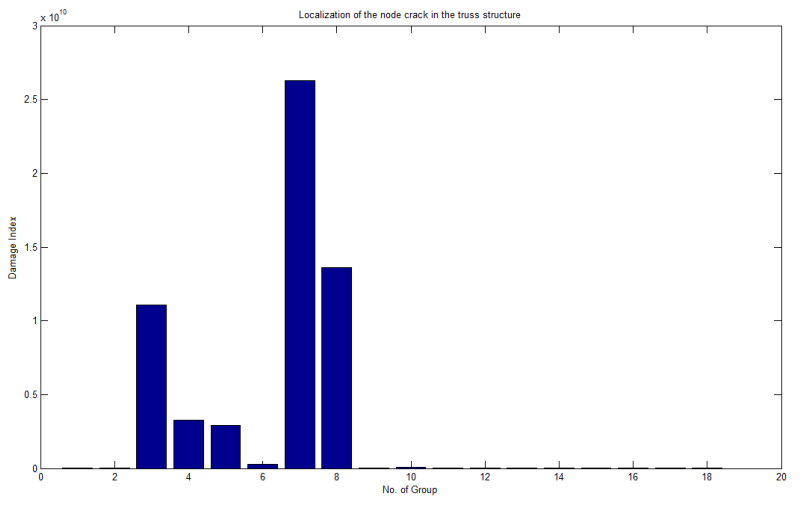

Fig. 4. DI calculated for areas (groups of sensors) of truss

As shown in figure 4 the method is able to detect the failure in the truss joint. Analyzing the DI values for the local modal filters one can notice that there is an increased level for area No. 3 and also for 4 and 5, which is predictable, but there are also big values for the groups of sensors No. 7 and 8 which is not so obvious especially for the latter.

Summarizing the localization is not as accurate as for the beam structure, but still it enables to more or less locate the area of structure where one should look for the damage.

\section{MONITORING OF LOAD CHANGES}

In this section the author will present the results of laboratory experiment on another kind of truss structure. This time the structure was not damaged but load with increasing force. The measurements could be successfully accomplished thanks to the courtesy of researchers from the Faculty of Automotive and Construction Machinery Engineering at Warsaw University of Technology. The object of the test was a single truss shown in figure 5 mounted on a specially built test stand in 


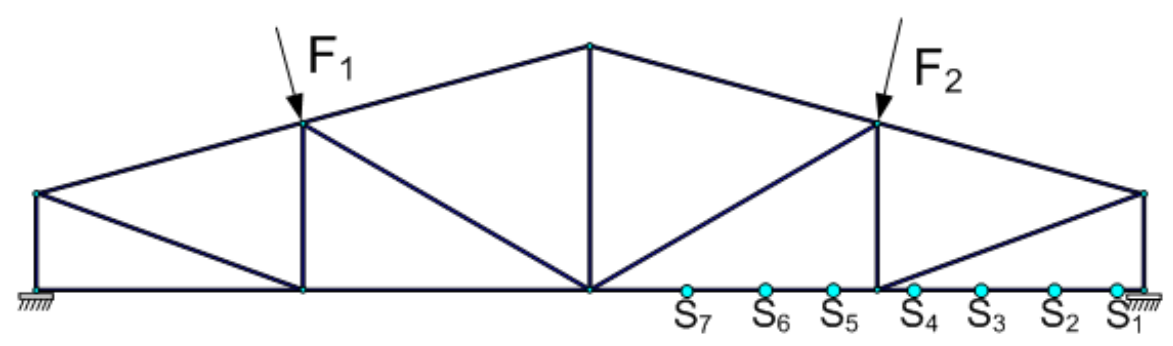

Fig. 5. Object of tests

the laboratories of the mentioned above Faculty (Gałęzia et al. 2012, Szulim et al. 2012). During the experiment a force was applied to the truss as shown in the figure. The main goal of the test was to prove that modal filtration can be successfully used for the detection of load changes for such objects.

The photo of measuring stand is presented below in figure 6. A set of sensors was installed on the bottom beam of the truss. A significant advantage of this approach is that it is not necessary to place a large number of sensors on the examined object even if it is large. The user can place only a few sensors evenly distributed on the object. The result in load changes monitoring efficiency would be very similar. However, a bit of experience is needed from the user to choose a proper area and sensors number. What is more, the position of each sensor cannot be changed during measurements, as it would affect damage detection quality (Mendrok and Uhl 2010b).

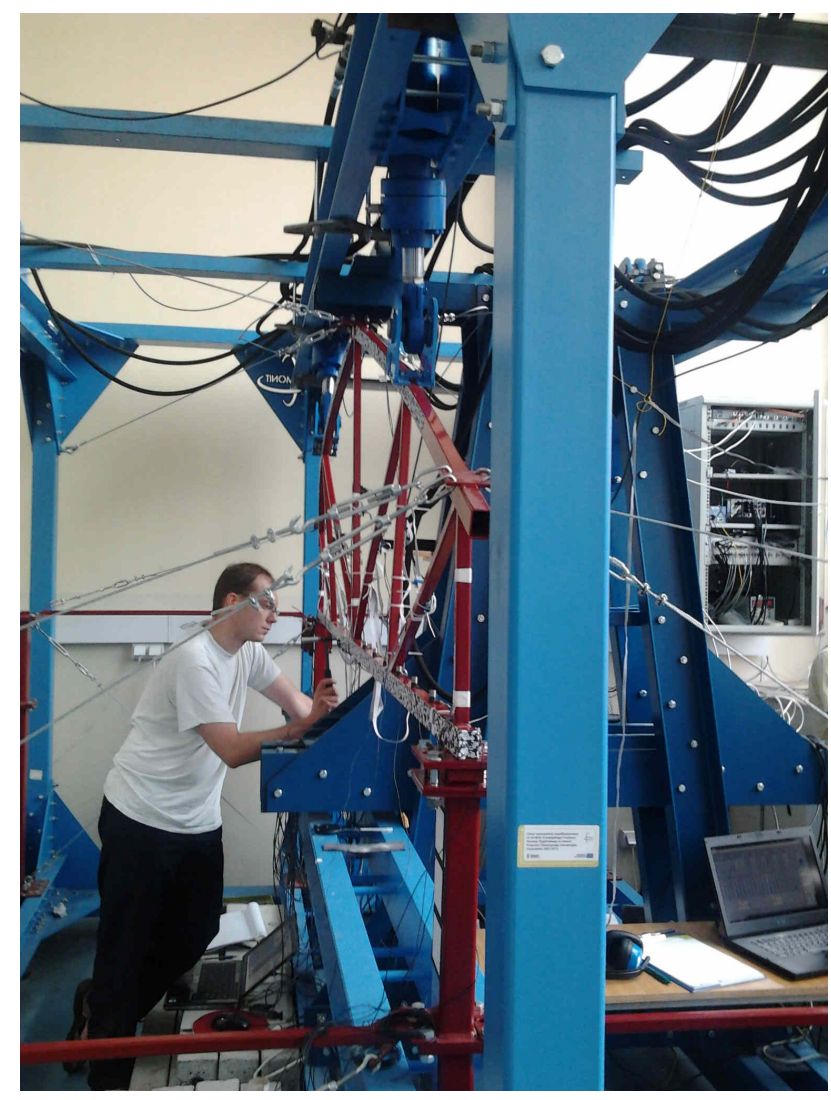

Fig. 6. Photo of the laboratory test stand
As a matter of fact this method can be successfully used in applications where the measures are performed periodically. In this case sensors do not need to be installed permanently, however, users have to ensure that every sensor is mounted exactly in the same point of the object as it was during reference measure. This can be achieved by using dedicated spacers (between object and sensors) mounted permanently on the tested object.

All the measurements and analysis were performed with use of dedicated hardware unit and software developed in the Department of Robotics and Mechatronics of AGH University of Science and Technology (Mendrok et al. 2012). At the very beginning modal test with impact excitation was performed. Next modal parameters and further reciprocal modal vectors were calculated. All these activities were performed for the object in the reference state. As reference state in this case the author understands the structure without loading.

The $0.1 \mathrm{~kg}$ modal hammer with force sensor was used to excite the structure. The responses were measured in the 7 points shown in figure 5 by one-axis accelerometers. The following parameters were used during the measurements: frequency bandwidth $-500 \mathrm{~Hz}$, spectral resolution $-0.25 \mathrm{~Hz}$. The measured characteristics (FRFs and power spectral densities) averaged 9 times in the frequency domain were recorded. In the last step the results of measurements were verified for their correctness. The ordinary coherence function and repeatability of the driving point FRF were the quality criteria. The modal parameters were estimated with the use of the LSFD algorithm, which was implemented in the software. The results obtained during the identification process are presented in figure 7 .

The last step of the reference data preparation consists in modal filter coefficients estimation. As a result, three modal filters had been calculated, each for different natural frequency and corresponding mode shape. Coefficients of these filters were then transferred to the measuring unit, which enabled it to work independently and calculate damage index values for each defined filter.

In the consecutive steps the load was slowly increased in several steps. The reference measurements were performed without load and the next load was applied with use of hydraulic drives. The load was increased up to $35 \mathrm{kN}$. Every $5 \mathrm{kN}$ the diagnostic procedure was launched and damage index was calculated. The $35 \mathrm{kN}$ load caused serious deformation of the tested truss. To see if the deformation is in the elastic range the load was released and increased again. 


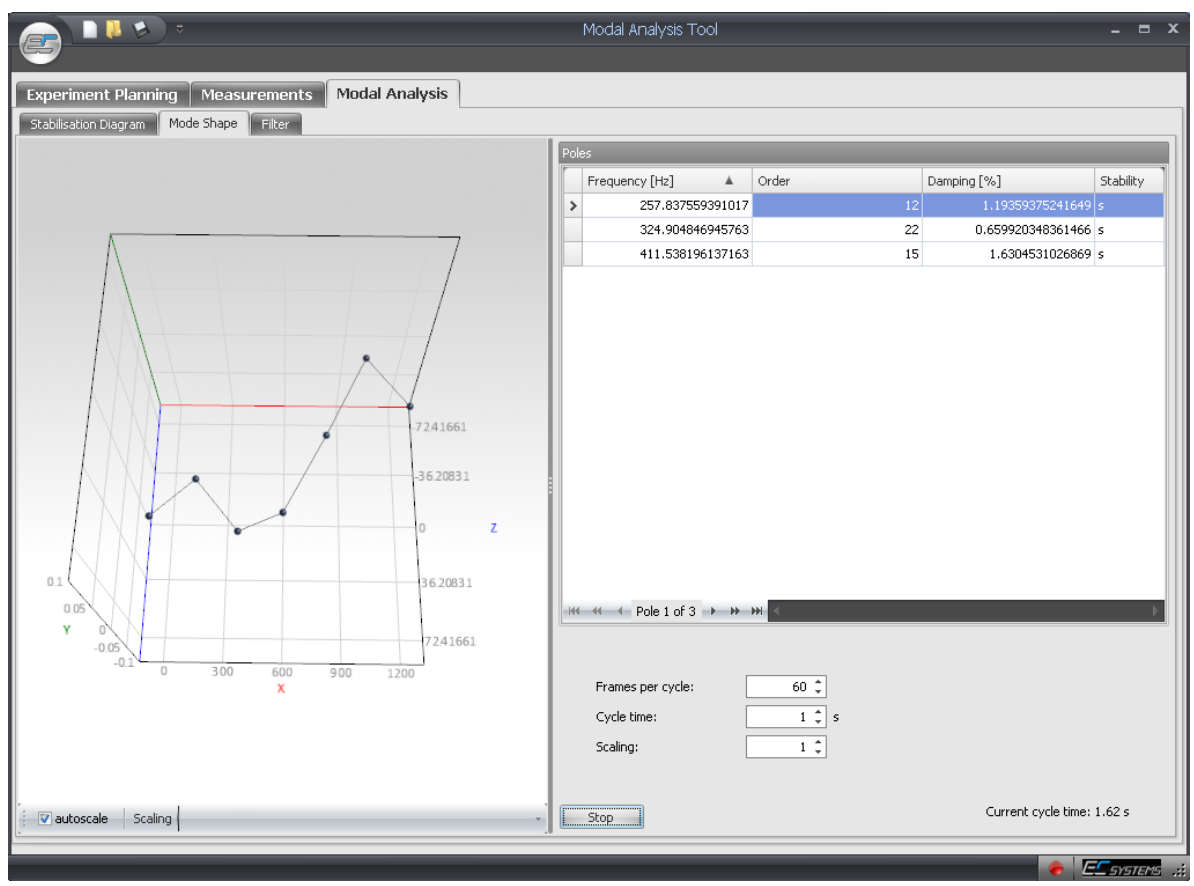

Fig. 7. Results of the modal analysis

At the level of $35 \mathrm{kN}$ the damage occurred. One of the clamps was broken and that ended the experiment. As it was stated earlier, every $5 \mathrm{kN}$ the DI values were calculated. They are gathered together in table 1.

Table 1

Values of DI calculated for modal filters tuned to mode shapes No. 1, 2 and 3

\begin{tabular}{|c|c|c|c|c|}
\hline \multirow{2}{*}{ No. } & \multicolumn{3}{|c|}{ Measurement Results } & \multirow{2}{*}{$\begin{array}{c}\text { Load } \\
{[\mathrm{kN}]}\end{array}$} \\
\cline { 2 - 4 } & DI(MF 1) & DI(MF 2) & DI(MF 3) & 0 \\
\hline 1 & $1.46 \mathrm{E}-02$ & $4.53 \mathrm{E}-02$ & $2.82 \mathrm{E}-02$ & 0 \\
\hline 2 & $8.07 \mathrm{E}-01$ & $8.17 \mathrm{E}-01$ & $4.00 \mathrm{E}-01$ & 5 \\
\hline 3 & $8.83 \mathrm{E}-01$ & $7.59 \mathrm{E}-01$ & $4.80 \mathrm{E}-01$ & 10 \\
\hline 4 & $9.60 \mathrm{E}-01$ & $9.24 \mathrm{E}-01$ & $6.98 \mathrm{E}-01$ & 20 \\
\hline 5 & $1.03 \mathrm{E}+00$ & $1.11 \mathrm{E}+00$ & $7.52 \mathrm{E}-01$ & 25 \\
\hline 6 & $1.11 \mathrm{E}+00$ & $1.30 \mathrm{E}+00$ & $8.31 \mathrm{E}-01$ & 30 \\
\hline 7 & $1.44 \mathrm{E}+00$ & $1.31 \mathrm{E}+00$ & $1.34 \mathrm{E}+00$ & 35 \\
\hline 8 & $8.54 \mathrm{E}-01$ & $8.71 \mathrm{E}-01$ & $7.10 \mathrm{E}-01$ & 15 \\
\hline 9 & $2.07 \mathrm{E}-01$ & $4.39 \mathrm{E}-01$ & $3.50 \mathrm{E}-01$ & 0 \\
\hline 10 & $1.35 \mathrm{E}+00$ & $1.16 \mathrm{E}+00$ & $1.13 \mathrm{E}+00$ & 35 \\
\hline
\end{tabular}

For better visualization of the results are presented as plot in figure 8 . Both table 1 and figure 8 exhibit a very clear trend of the damage index value. It grows together with load increase. Especially, the modal filter tuned to Mode shape 3 presents linear dependency. It indicates that the method and SHM system based on it can detect not only damage but also the load change. This is the information that the author wanted to prove and thanks to that one system can be used for entire monitoring, both for damage and load change detection.



Fig. 8. Values of DI in function of load

Another interesting point is that after complete load release the damage index did not returned to the 0 value. It means that the $35 \mathrm{kN}$ load introduced some structural changes to the structure. These results were confirmed by the camera-based measurements of the structure deflection (Kohut et al. 2013). After the load release the truss did not return to its original shape.

\section{CONCLUSIONS}

The paper presents the trial of application of modal filtration to complex monitoring of the civil engineering objects of trusslike structure. The author verified if it is possible to detect and localize the damage in the joint of the truss structure and also checked if the method can be applied to load changes 
monitoring. For this purpose, both numerical and experimental data were used. In the first case it was proved that it is possible to detect breakage in the truss joint with the method based on modal filtration. Also the localization of the failure is possible but not as accurate as for the crack localization in the beam or plate. The author also showed that the tested method is able to give the indication of changing load. That is why the method seems to be a good candidate for the structural health monitoring system of the civil engineering structures like bridges or viaducts.

\section{References}

Carden P., Fanning P., 2004, Vibration Based Condition Monitoring: A Review. Structural Health Monitoring, 3(4), 355-377.

Doebling S.W., Farrar C.R., Prime M.B., 1998, A Summary Review of Vibration-Based Damage Identification Methods. The Shock and Vibration Digest, 30(2), 91-105.

Gałęzia A., Gontarz S., Jasiński M., Mączak J., Radkowski S., Seńko J., 2012 Distributed system for monitoring the large scale infrastructure struc tures based on changes analysis of its static and dynamic properties. Key Engineering Materials, 518, 106-118.

Kohut P., Holak K., Mendrok K., Maj W., 2013, Structure's damage detection supported by contact and contact-less global methods. Diagnostyka, 14(1), 47-56.
Meirovitch L., Baruh H., 1982, Control of Self-Adjoint Distributed Parameter System. Journal of Guidance Control and Dynamics, 8(6), 60-66.

Mendrok K., Uhl T., 2004, Overview of Modal Model-based Damage Detection Methods. Proc. of 2004 ISMA, Leuven, Belgium.

Mendrok K., Uhl T., 2008, Modal filtration for damage detection and localization. [in:] Structural health monitoring 2008 Proc. of the Fourth European Workshop: Krakow, Poland, July 2-4, 2008, T. Uhl, W. Ostachowicz, J. Holnicki-Szulc (eds), Lancaster, Pennsylvania: DEStech, Publications, 929-936.

Mendrok K., Uhl T., 2010a, The application of modal filters for damage detection. Smart Structures and Systems, 6(2) 115-133.

Mendrok K., Uhl T., 2010b, Numerical tests of a damage detection procedure based on modal filtration. [in:] F. Casciati, M. Giordano (eds), Proc. of the fifth European workshop Structural Health Monitoring 2010: June 28 - July 4, 2010, 982-987.

Mendrok K., Uhl T., 2011, Experimental verification of the damage localization procedure based on modal filtering. Structural Health Monitoring, 10(2), 157-171.

Mendrok K., Uhl T., Maj W., Paćko P., 2012, SHM system based on modal filtration. Key Engineering Materials, 518, 289-297.

Szulim P., Lubikowski K., Mączak J., Rokicki K., 2012, Low-budget magnetic field transducers for construction diagnosis. Proc. of the Institute of Vehicles, 3(89).

Zhang Q., Allemang R.J., Brown D.L., 1990, Modal Filter: Concept and Applications. Proc. of 8th International Modal Analysis Conference Orlando FL USA, 487-496. 